Supporting Information

(22 pages, including 14 Figures and 1 Table)

\title{
In Situ Synthesis of Ternary NiCoRu-based Layered Double Hydroxide by Chlorine Corrosion toward Electrocatalytic Water Oxidation
}

Shaoyun Hao,${ }^{\dagger}$ Guokui Zheng, ${ }^{\dagger}$ Shaojie Gao,${ }^{\dagger}$ Lingshu Qiu, ${ }^{\dagger}$ Nan Xu,${ }^{\dagger}$ Yi He,${ }^{\dagger}$ Lecheng Lei, ${ }^{\dagger \dagger}$

Xingwang Zhang*,†;

†Key Laboratory of Biomass Chemical Engineering of Ministry of Education, College of Chemical and Biological Engineering, Zhejiang University, Zheda Road 38, Hangzhou, Zhejiang

Province 310027, China

${ }^{\ddagger}$ Institute of Zhejiang University-Quzhou, Quzhou 324000, China

*E-mail: xwzhang@zju.edu.cn 


\section{Contents}

Experimental section..........................................................................

Figure S1 SEM, TEM, Elemental maps, and HAADF-STEM images of NiCo-LDH obtained

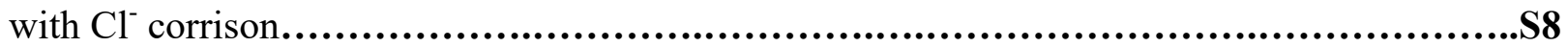

Figure S2 SEM, TEM, Elemental maps, and HAADF-STEM images of NiRu-OH obtained with $\mathrm{Cl}^{-}$corrison.

Figure S3 SEM, TEM, Elemental maps, and HAADF-STEM images of $\mathrm{NiCo}_{2} \mathrm{Ru}-\mathrm{LDH}$ obtained with $\mathrm{Cl}^{-}$corrison. S10

Figure S4 SEM, TEM, Elemental maps, and HAADF-STEM images of NiCoRu $\mathrm{NLDH}_{2}$ obtained with $\mathrm{Cl}^{-}$corrison. S11

Figure S5 EDX spectra for these prepared multimetallic hydroxide supported on NF. .512

Figure S6 XRD patterns for these prepared multimetallic hydroxide supported on NF . $\mathrm{S13}$

Figure S7 Ru 3d and Raman spectrum for these prepared multimetallic hydroxide supported on NF. S14

Figure S8 XPS survey patterns of NiCo-LDH, NiRu-OH, NiCoRu-LDH.......................S15

Figure S9 CV curves of these prepared multimetallic hydroxide supported on NF. S16

Figure S10 EIS analysis of these prepared multimetallic hydroxide supported on NF.............S17

Table S1 Comparison with some representative Ni-based OER catalysts.....................S18

Figure S11 The volume of $\mathrm{O}_{2}$ generated by the NiCoRu-LDH/NF for OER.................S19

Figure S12 SEM, TEM, HR-TEM, and Elemental images for NiCoRu-LDH after OER........S20

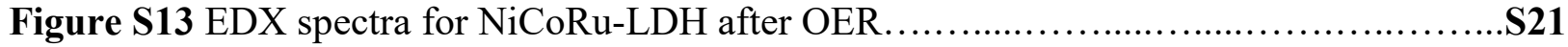

Figure S14 XRD pattern for NiCoRu-LDH after OER reaction ............................S22 
Materials and Methods

Materials: Nickel foam (1 mm, thick) was purchased from Jiashide Foam Metal Co., Ltd. (Suzhou, China). These reagents including, $\mathrm{NaCl}, \mathrm{KOH}$, ethanol, acetone, $\mathrm{RuCl}_{3}$, and $\mathrm{CoCl}_{2} \cdot 6 \mathrm{H}_{2} \mathrm{O}$ all got from Sinopharm Chemical Reagent Co., Ltd. Ultrapure Milli-Q water was applied to prepare electrolytes and wash samples.

Preparation of NiCo-LDH nanosheets

Prior to the synthesis, a piece of $2 \times 2 \mathrm{~cm}^{2} \mathrm{NF}$ was respectively ultrasonicated with $\mathrm{HCl}(1 \mathrm{M})$, acetone, and ethanol maintaining $15 \mathrm{~min}$ to ensure that there is no oxide and the other materials on the surface of the NF.

The synthesis of NiCo-LDH (NiRu-OH) nanosheets was according to the following way: a piece of $\mathrm{NF}$ was put into a conical flask containing $\mathrm{NaCl}(0.5 \mathrm{M})$ and $\mathrm{CoCl}_{2} \cdot 6 \mathrm{H}_{2} \mathrm{O}\left(\mathrm{RuCl}_{3}\right)(0.5$ $\mathrm{mM}$ ). Then, the conical flask was placed into water bath with the temperature of $353 \mathrm{~K}$ for $6 \mathrm{~h}$. Afterwards, Milli-Q water was served to wash the collected NF three times. Finally, argon gas was employed to dry NF for $5 \mathrm{~min}$.

Preparation of NiCoRu-LDH nanosheets

A piece of $\mathrm{NF}$ was put into a conical flask containing $\mathrm{NaCl}(0.5 \mathrm{M}), \mathrm{CoCl}_{2} \cdot 6 \mathrm{H}_{2} \mathrm{O}(0.25 \mathrm{mM})$, and $\mathrm{RuCl}_{3}(0.25 \mathrm{mM})$. Then, the conical flask was placed into water bath with the temperature of $353 \mathrm{~K}$ for $6 \mathrm{~h}$. Afterwards, Milli-Q water was served to wash the collected NF three times. Finally, argon gas was employed to dry NF for $5 \mathrm{~min}$.

Preparation of $\mathrm{NiCo}_{2} \mathrm{Ru}-\mathrm{LDH}$ nanosheets

A piece of $\mathrm{NF}$ was put into a conical flask containing $\mathrm{NaCl}(0.5 \mathrm{M}), \mathrm{CoCl}_{2} \cdot 6 \mathrm{H}_{2} \mathrm{O}(0.5 \mathrm{mM})$, and $\mathrm{RuCl}_{3}(0.25 \mathrm{mM})$. Then, the conical flask was placed into water bath with the temperature of $353 \mathrm{~K}$ for $6 \mathrm{~h}$. Afterwards, Milli-Q water was served to wash the collected NF three times. Finally, argon gas was employed to dry NF for $5 \mathrm{~min}$.

Preparation of $\mathrm{NiCoRu}_{2}-\mathrm{LDH}$ nanosheets

A piece of $\mathrm{NF}$ was put into a conical flask containing $\mathrm{NaCl}(0.5 \mathrm{M}), \mathrm{CoCl}_{2} \cdot 6 \mathrm{H}_{2} \mathrm{O}(0.25 \mathrm{mM})$, and $\mathrm{RuCl}_{3}(0.5 \mathrm{mM})$. Then, the conical flask was placed into water bath with the temperature of 
$353 \mathrm{~K}$ for $6 \mathrm{~h}$. Afterwards, Milli-Q water was served to wash the collected NF three times. Finally, argon gas was employed to dry NF for $5 \mathrm{~min}$.

The detailed mechanism can be illustrated as follows:

First, at the anode region, the $\mathrm{Ni}$ foam could be corroded to $\mathrm{Ni}^{2+}$ cations in a relatively high concentration of $\mathrm{Cl}^{-}$solution. Then, the $\mathrm{Cl}^{-}$continuously migrated and enriched the anode region. Simultaneously, at the cathode side, the oxygen from the air or water reacted with water to form hydroxide $\left(\mathrm{OH}^{-}\right)$. Finally, the $\mathrm{M}^{\mathrm{x}+}$ cations and the diffusion of $\mathrm{Ni}^{2+}$ synchronously reacted with $\mathrm{OH}^{-}$to precipitate and form multimetallic hydroxide nanosheet arrays supporting on NF. The possible reactions are:

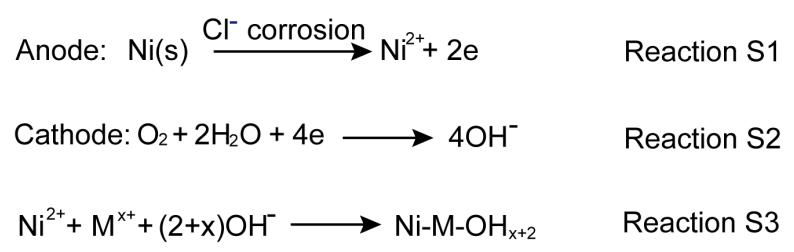

\section{Characterizations:}

For XRD, a Rigaku D/Max 2400 X-ray diffractometer furnished with $\mathrm{Cu} \mathrm{K} \alpha$ radiation was employed to collect the data of these multimetallic hydroxides supported on NF. A SU-80 (Hitachi) microscope working at $20 \mathrm{kV}$ was applied to observe and acquire the SEM images. The FEI Titan $\mathrm{G}^{2} 80-200$ Chemi STEM performing at $200 \mathrm{kV}$ was used to get the data of TEM and HAADR-STEM, HR-STEM, and elemental maps. A Kratos Axis Ultra DLD with Mg Ka X-ray line working at $2 \mathrm{kV}$ was employed to characterize the samples. Raman scattering spectra were recorded with a LabRAM HR Evolution (Horiba) using the $514.5 \mathrm{~nm}$ line of $\mathrm{Ar}^{+}$for excitation.

\section{Electrochemical measurements}

All the electrochemical activities of the prepared electrodes were conducted on a Bio-Logic VSP potentiostat with a standard three-electrode system. The prepared NiCo-LDH/NF, $\mathrm{NiRu}-\mathrm{OH} / \mathrm{NF}, \mathrm{NiCoRu}-\mathrm{LDH} / \mathrm{NF}, \mathrm{NiCo}_{2} \mathrm{Ru}-\mathrm{LDH} / \mathrm{NF}$, and $\mathrm{NiCoRu}_{2}-\mathrm{LDH} / \mathrm{NF}\left(1 \times 0.5 \mathrm{~cm}^{2}\right)$ were respectivly acted as working electrodes. Meanwhile, the graphite rod and an $\mathrm{Ag} / \mathrm{AgCl}$ full of $1 \mathrm{M}$ $\mathrm{KCl}$ were worked as counter and the reference electrodes, respectively. The activities of these prepared electrodes toward OER were all characterized by linear sweep voltammetry (LSV) in 
an electrolytic cell containing $1 \mathrm{M} \mathrm{KOH}(100 \mathrm{~mL})$ with purging $\mathrm{O}_{2}$ for $30 \mathrm{~min}$. Additionally, all the curves of LSV were calibrated via $i \mathrm{R}$ correction. All the measuring potentials were transformed into reversible hydrogen electrode. Similarly, the stabilities of NiCoRu-LDH/NF all performed in the solution of $\mathrm{O}_{2}$-saturated $1 \mathrm{M} \mathrm{KOH}$ solution at a constant current density of 100 $\mathrm{mA} \cdot \mathrm{cm}^{-2}$ towards OER. All the EIS measurements were conducted at the onset potential from $0.01 \mathrm{~Hz}$ to $100 \mathrm{kHz}$. Moreover, the commercial $\mathrm{IrO}_{2} / \mathrm{C}\left(20 \%, 1 \mathrm{mg} \cdot \mathrm{cm}^{-2}\right)$ were used towards OER as the comparative test. The double layered capacitances $\left(C_{\mathrm{dl}}\right)$ of these fabricated electrodes were respectively estimated by $\mathrm{CV}$ curves from 0.11 to $0.21 \mathrm{~V}$ and 0.965 to $1.065 \mathrm{~V}$ vs RHE towards HER and OER with different scan rates. The collected current densities were liner with the scan rates, thus calculating $C_{\mathrm{dl}}$ from the fitting line. The mass-loading of $\mathrm{NiCoRu}-\mathrm{LDH} / \mathrm{NF}$ was determined by weighing the powder stripped with ultrasonication from NF. The NF was ultrasonicated in a solution containing ethanol for two hours. The catalyst powder in the solution was centrifuged and dried in a vacuum drying oven at $333 \mathrm{~K}$.

The obtained current densities at the selected potential have the linear relationship with the scan rates and the slopes of fitting curves were considered as the $\mathrm{C}_{\mathrm{dl}}$. We applied the specific capacitance $\left(20-60 \mu \mathrm{F} \cdot \mathrm{cm}^{-2}\right)$ of $40 \mu \mathrm{F} \cdot \mathrm{cm}^{-2}$ here to calculate the ECSA.

$$
\mathrm{ECSA}=\mathrm{C}_{\mathrm{d} 1} / \mathrm{C}_{\mathrm{s}} \times \mathrm{ASA} \quad(\text { Equation } \mathrm{S} 1)
$$

The $\mathrm{C}_{\mathrm{s}}$ and ASA are the specific capacitance and the actual surface area of the fabricated $\mathrm{Ni}$ foam, respectively.

Calculation of Faradaic efficiency

The Faradaic efficiency (FE) for NiCoRu-LDH in $1 \mathrm{M} \mathrm{KOH}$ solution toward HER was carried out in a three-electrode configuration and detected by a gas chromatography (GC, 9790II, Hangzhou Gatai Scientific Instruments). The electrolyte and cell were first degassed with Argon for 30 min under stirring. Afterwards, a constant current of $10 \mathrm{~mA}$ was applied for a certain period of time. At the end of electrolysis, the gaseous samples were drawn from the head space by a gas tight syringe and analyzed by a GC calibrated for $\mathrm{H}_{2}$. Each injection was repeated at least three times and the average value is presented. 
The Faradaic efficiency (FE) is calculated based on the following equation:

$$
\mathrm{FE}\left(\mathrm{H}_{2}, \%\right)=\mathrm{V}_{\mathrm{H} 2} * 2 * \mathrm{~F} / \mathrm{V}_{\mathrm{m}} *_{\mathrm{i}} *_{\mathrm{t}} * 100 \% \quad \text { (Equation } \mathrm{S} 2 \text { ) }
$$

$\mathrm{V}_{\mathrm{H} 2}$ was the evolved volume of $\mathrm{H}_{2}, \mathrm{~F}$ is the Faraday constant $(96485.33289 \mathrm{C} / \mathrm{mol}), \mathrm{V}_{\mathrm{m}}$ is the molar volume of the gas, $\mathrm{i}$ is the current, and $\mathrm{t}$ is the time for electrolysis. 


\section{Theoretical calculation}

The density-functional theory (DFT) calculations in this work were performed using the Vienna Ab-initio Simulation Package (VASP). ${ }^{1,2}$ The Blöchl's all-electron-like projector augmented plane wave (PAW) method was used to describe the interactions between ion cores and valence electrons. ${ }^{3,4}$ The electron exchange-correlation interaction was treated using the generalized gradient approximation (GGA) with the Perdew-Burke-Ernzerhof (PBE) functional. A Hubbard-U correction (DFT $+\mathrm{U}$ method) was applied in the simulations, in order to improve the on-site Coulomb interactions for NiCo-LDH. In the present work, the value of $\mathrm{U}$ is 3.8 for $\mathrm{Ni}$, and 4.0 for Co. The plane waves with a cutoff energy of $400 \mathrm{eV}$ were used, and the $3 \times 3 \times 1$ Monkhorst-Pack grid k-points were employed to sample the Brillouin zone integration. The structures were optimized until the energy and the force were converged to $1.0 \times 10^{-5} \mathrm{eV} /$ atom and $0.02 \mathrm{eV} / \AA$, respectively. A vacuum space as large as $15 \AA$ was used along the c direction normal to the catalyst surface to avoid periodic interactions.

As shown in Figure. 4 in the main text, a slab with NiCo LDH layer surface was constructed to simulate the reaction condition of $\mathrm{NiCo} \mathrm{LDH}$ during OER process. The corresponding simulation model is denoted as NiCo-LDH. For the Ru-doped NiCo-LDH model, we replaced Co with Ru sites in a pristine NiCo-LDH model. During structure optimization, the absorbates involved in $\mathrm{OER}$ were $\mathrm{O}^{*}, \mathrm{OH}^{*}, \mathrm{OOH}^{*}, \mathrm{OH}^{*}-\mathrm{OH}^{*}$ and $\mathrm{O}_{2} *$.

References

(1) G. Kresse, Kresse G., Hafner J., Ab Initio Molecular Dynamics for Liquid Metals. Phys. Rev. $B$ 1993, 47, 558-561.

(2) Kresse G., Hafner J., Ab Initio Molecular-Dynamics Simulation of the Liquid-Metal--Amorphous-Semiconductor Transition in Germanium. Phys. Rev. B 1994, 49 (20), 14251-14269.

(3) Blöchl P. E., Projector Augmented-Wave Method. Phys. Rev. B 1994, 50 (24), 17953-17979.

(4) Kresse G., Joubert D., From Ultrasoft Pseudopotentials to the Projector Augmented-Wave Method. Phys. Rev. B 1999, 59 (3), 1758-1775. 

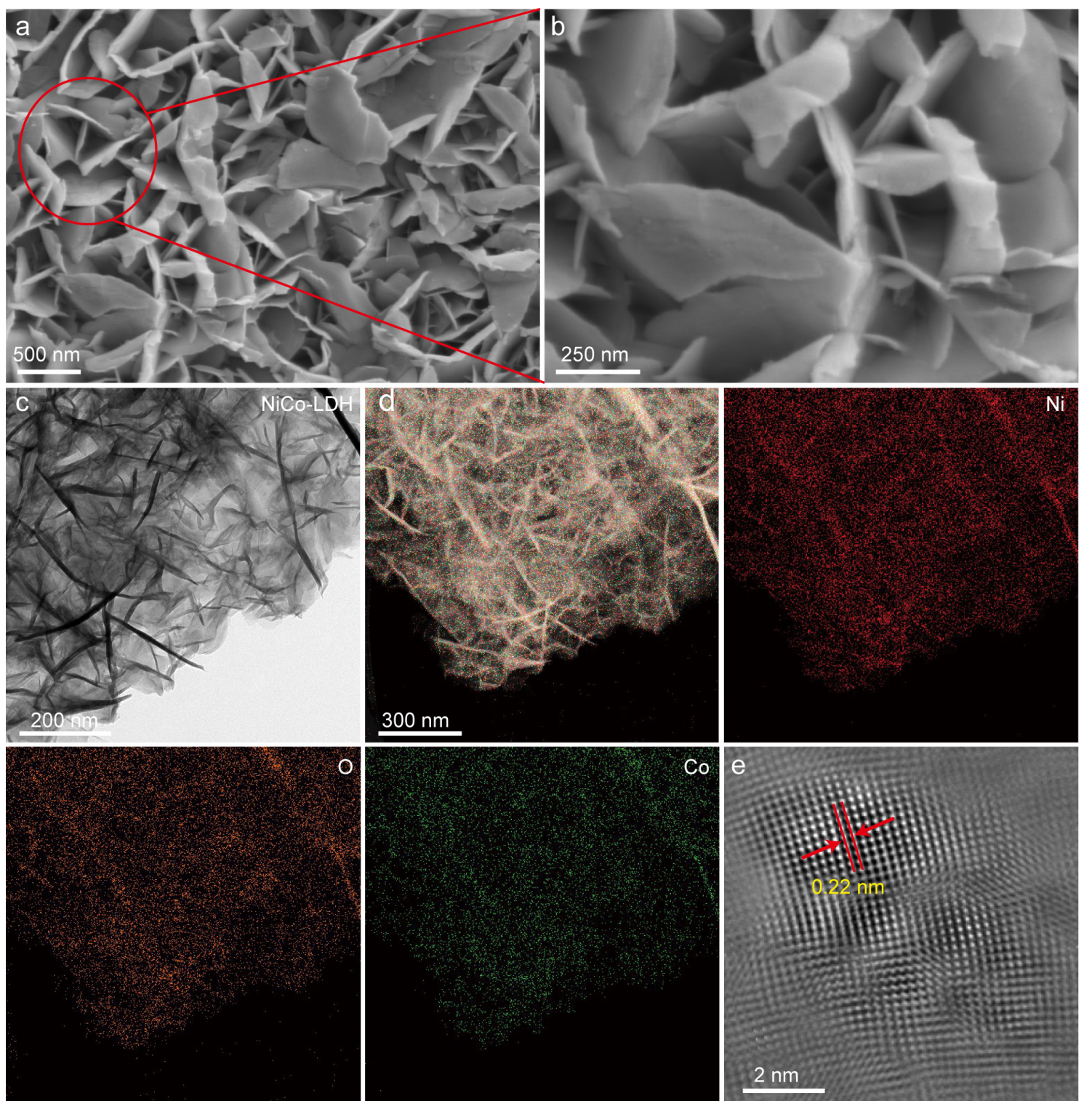

Figure S1. SEM images (a, b), TEM image (c), Elemental maps (d), and HAADF-STEM image (e) for NiCo-LDH. 


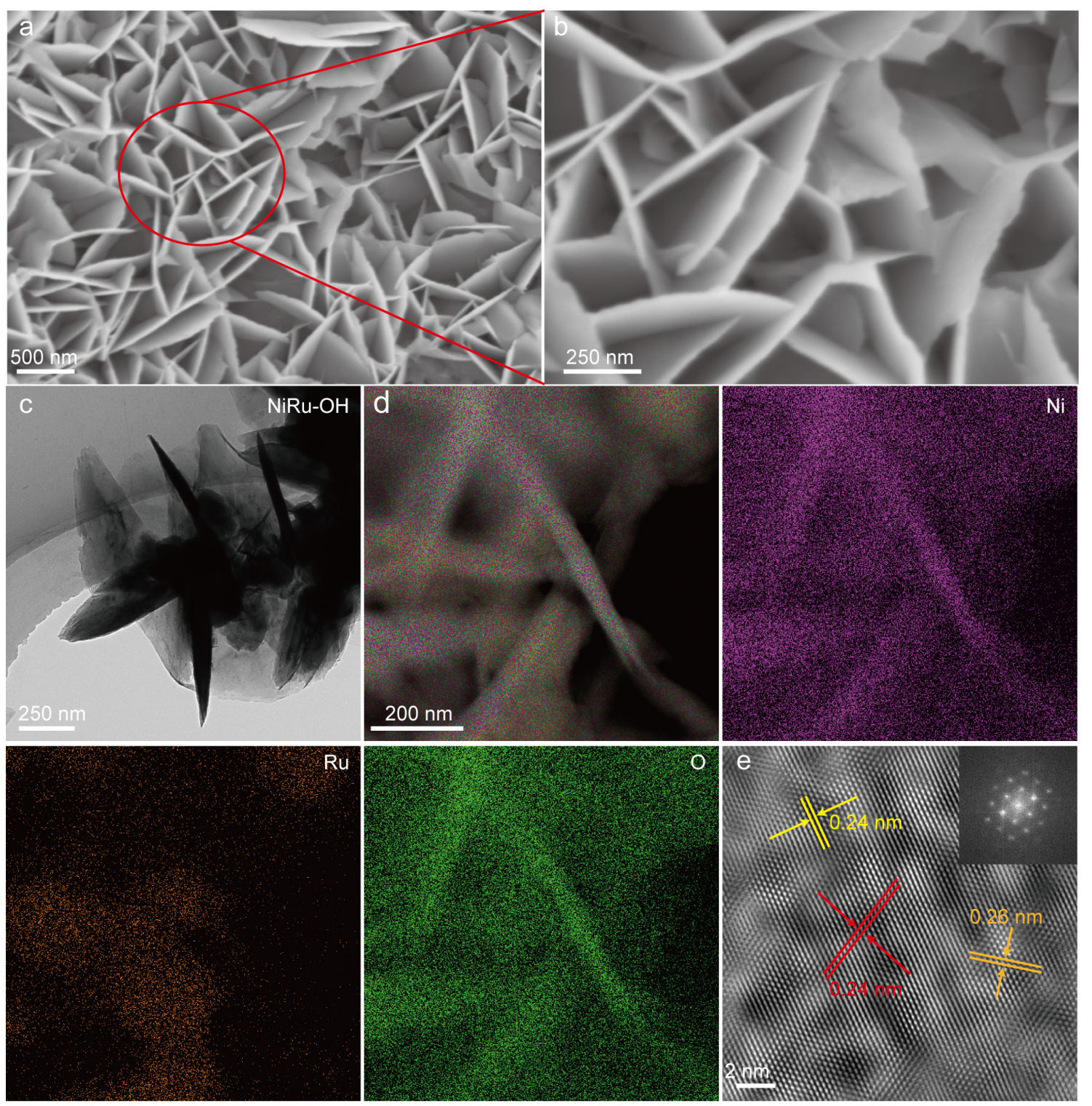

Figure S2. SEM images (a, b), TEM image (c), Elemental maps (d), and HAADF-STEM image (e) for NiRu-OH. 

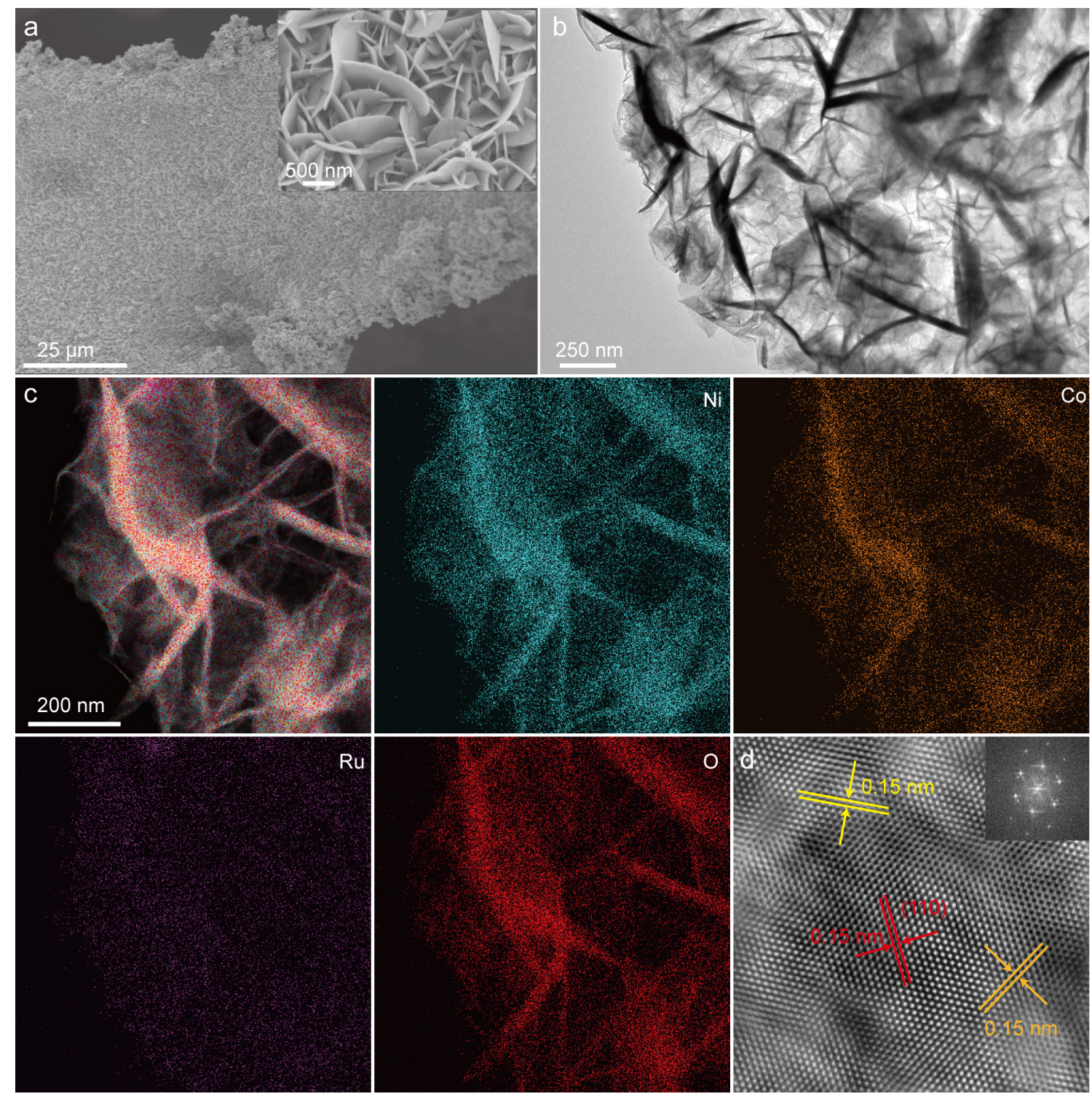

Figure S3. SEM images (a, b), TEM image (c), Elemental maps (d), and HAADF-STEM image (e) for $\mathrm{NiCo}_{2} \mathrm{Ru}-\mathrm{LDH}$. 

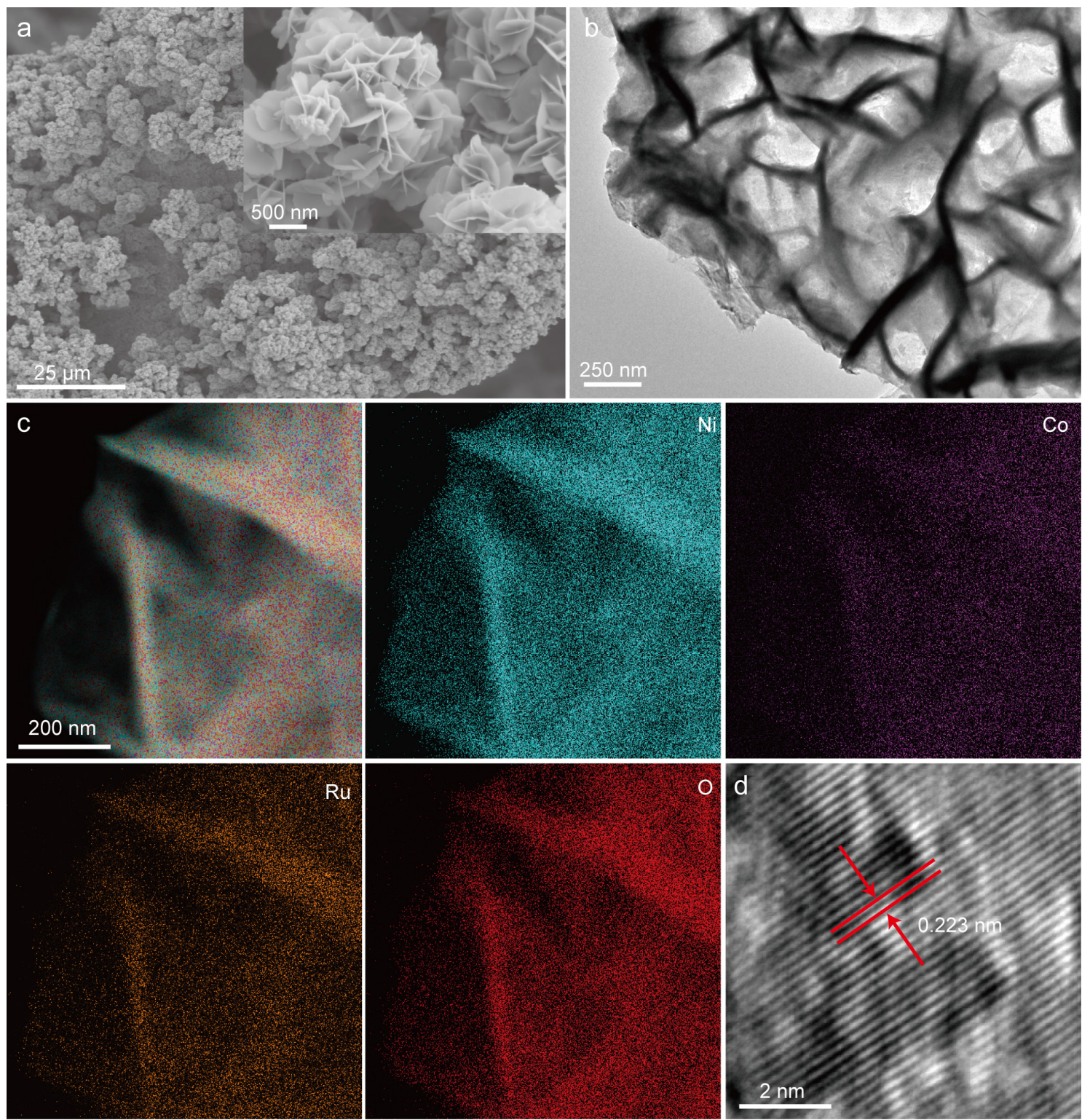

Figure S4. SEM images (a, b), TEM image (c), Elemental maps (d), and HAADF-STEM image (e) for $\mathrm{NiCoRu}_{2}-\mathrm{LDH}$ 

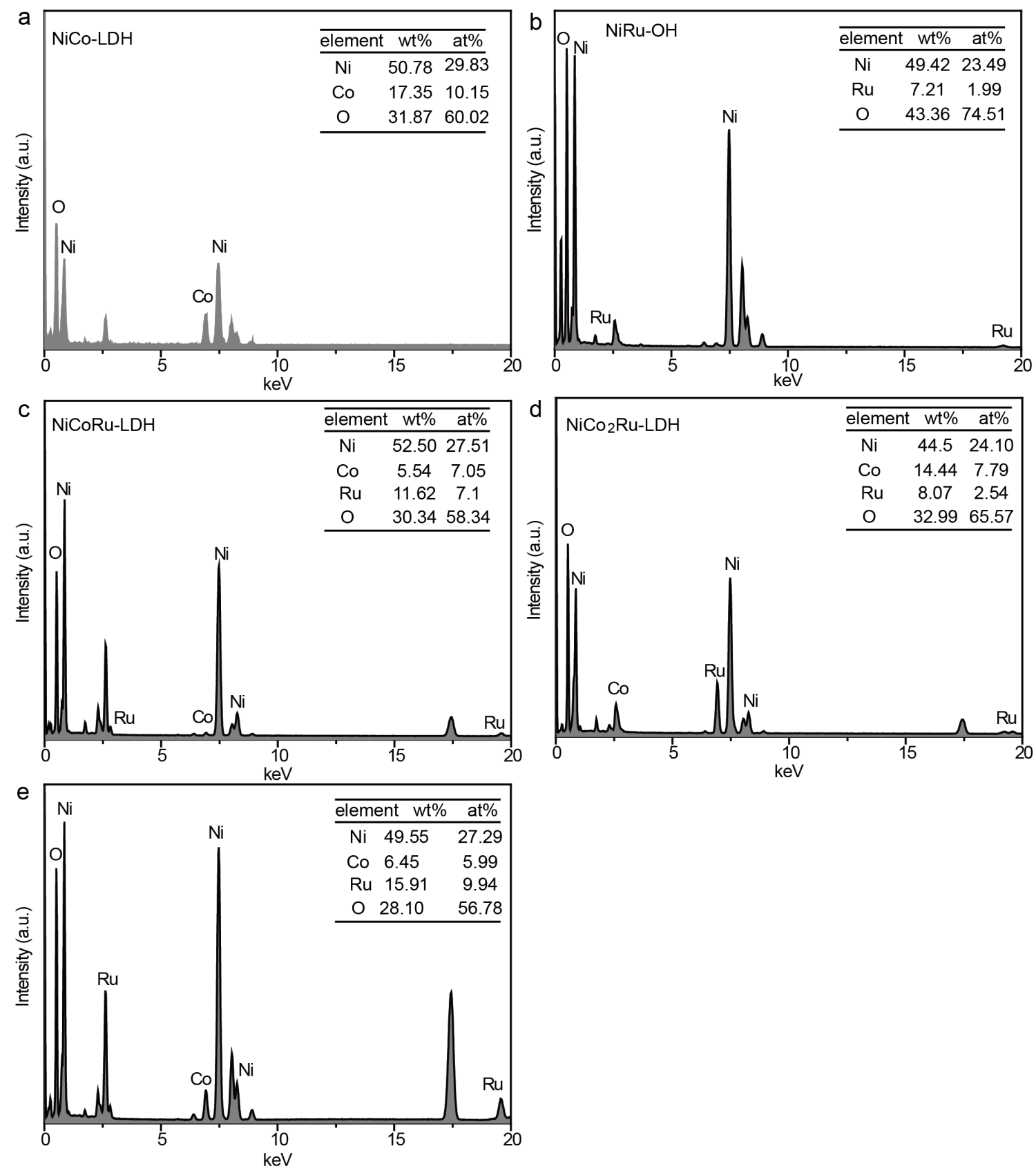

Figure S5. EDX spectra for (a) NiCo-LDH, (b) NiRu-OH, (c) NiCoRu-LDH, (d) $\mathrm{NiCo}_{2} \mathrm{Ru}-\mathrm{LDH}$, and (e) $\mathrm{NiCoRu}_{2}-\mathrm{LDH}$. 

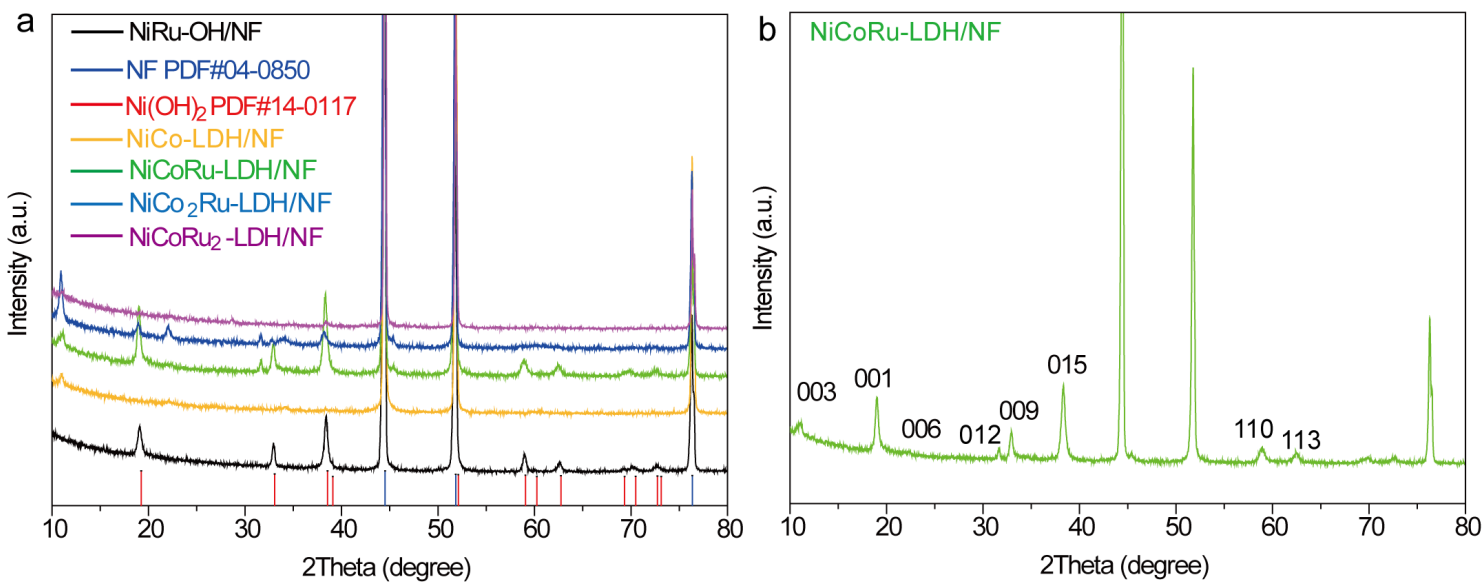

Figure S6. (a) XRD patterns for NF, NiRu-OH/NF, NiCo-LDH/NF, NiCoRu-LDH/NF, $\mathrm{NiCo}_{2} \mathrm{Ru}-\mathrm{LDH} / \mathrm{NF}$, and $\mathrm{NiCoRu}_{2}-\mathrm{LDH} / \mathrm{NF}$. (b) XRD pattern for NiCoRu-LDH/NF. 

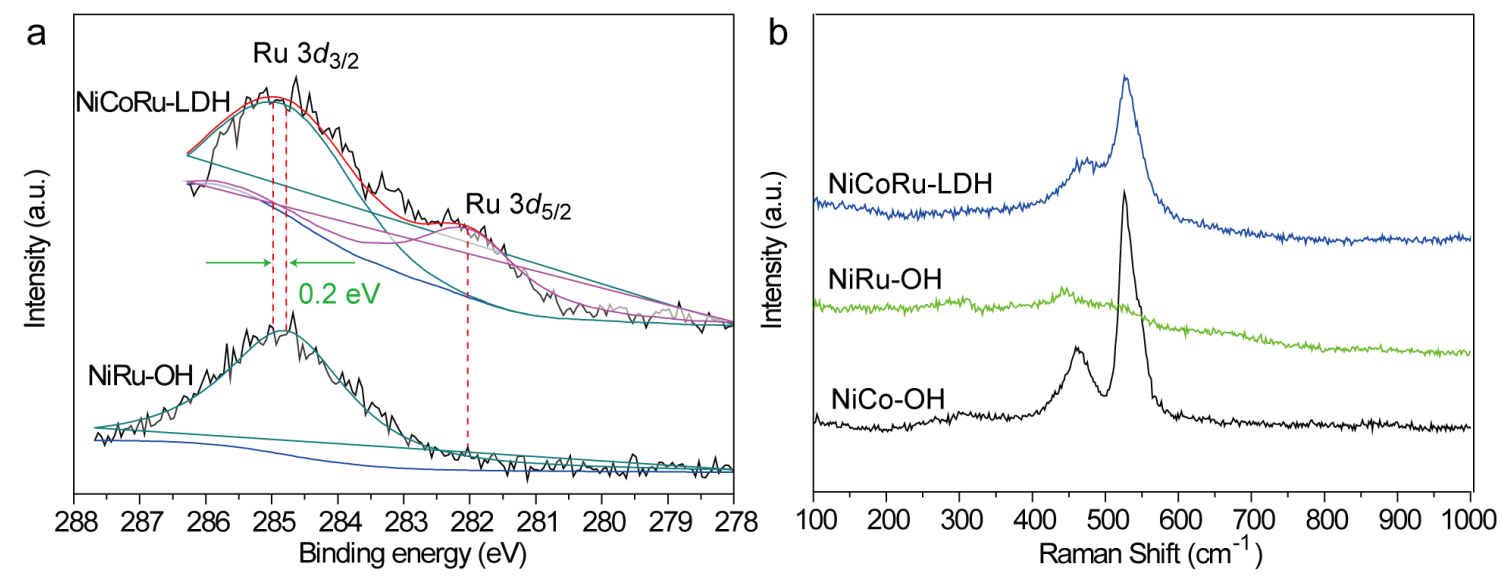

Figure S7. (a) The XPS spectra for Ru 3d for NiRu-OH and NiCoRu-LDH. (b) The Raman spectra for NiCo-LDH, NiRu-OH, and NiCoRu-LDH. 


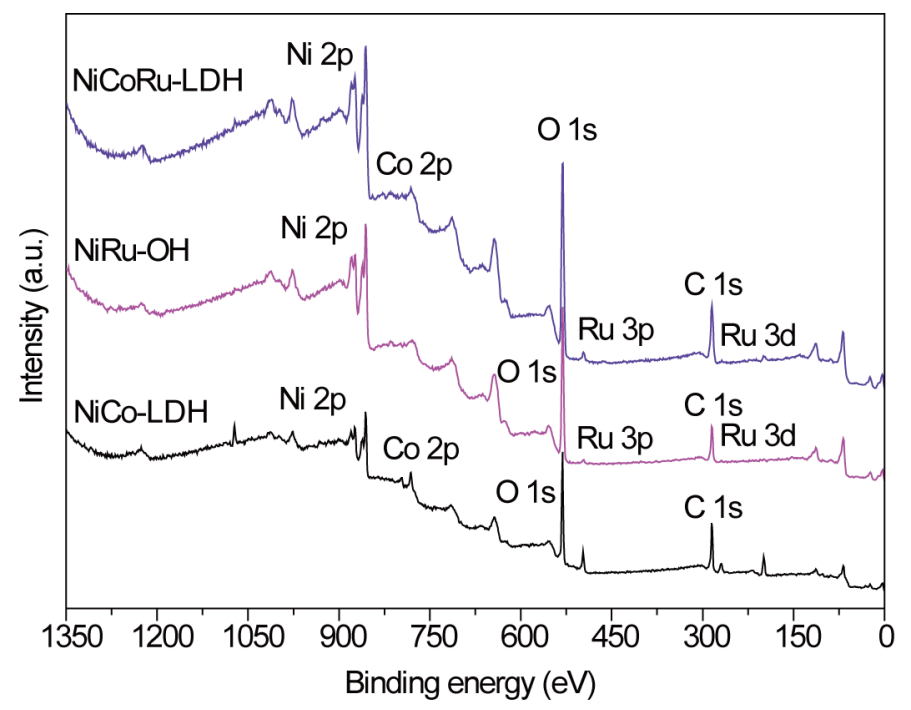

Figure S8. XPS full survey patterns of NiCo-LDH, NiRu-OH, NiCoRu-LDH. 

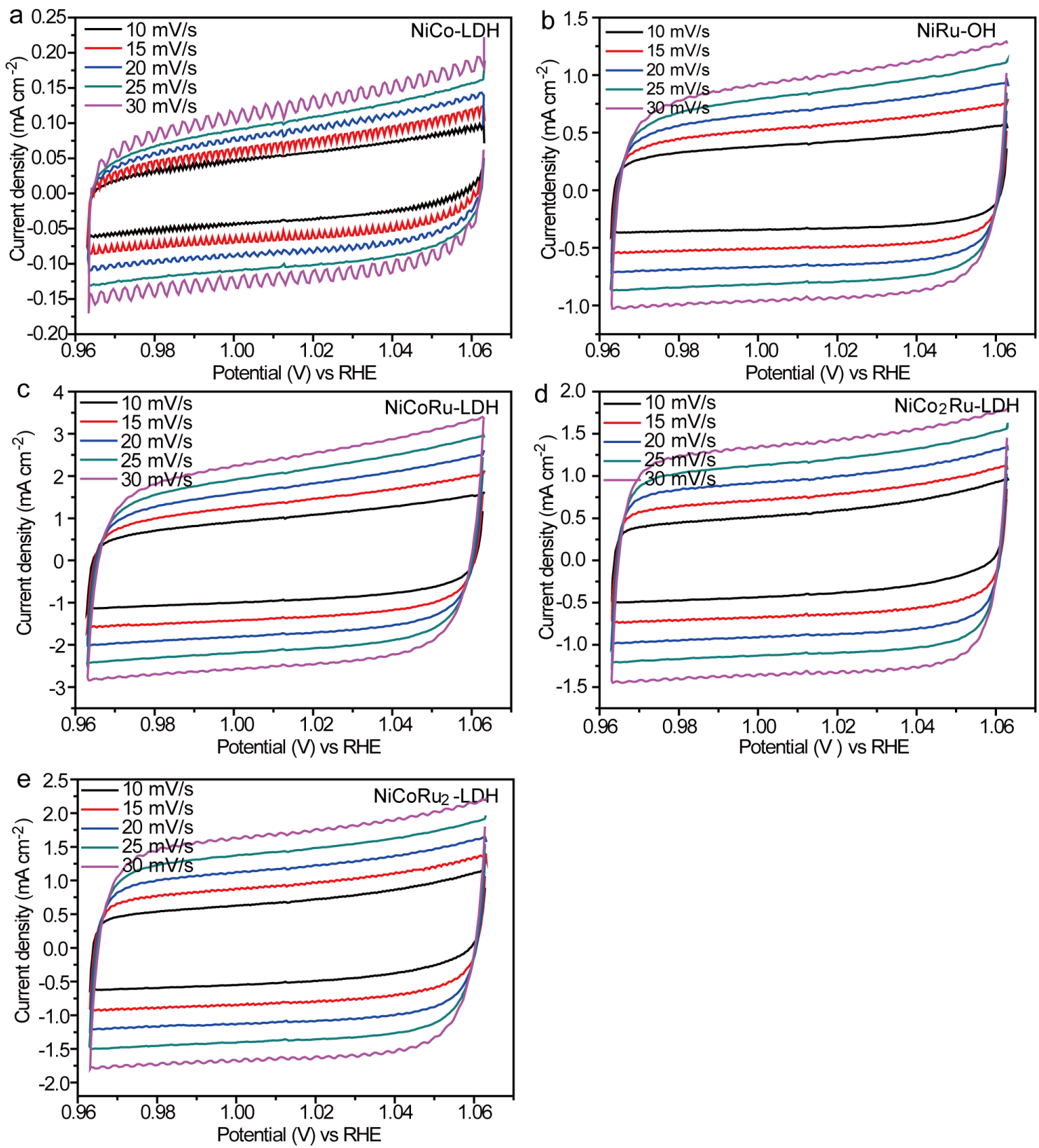

Figure S9. Non-Faradaic scan for double-layer capacitance. Cyclic voltammetry of (a) NiCo-LDH, (b) NiRu-OH, (c) NiCoRu-LDH, (d) $\mathrm{NiCo}_{2} \mathrm{Ru}-\mathrm{LDH}$, and (e) $\mathrm{NiCoRu}_{2}-\mathrm{LDH}$ toward OER. 


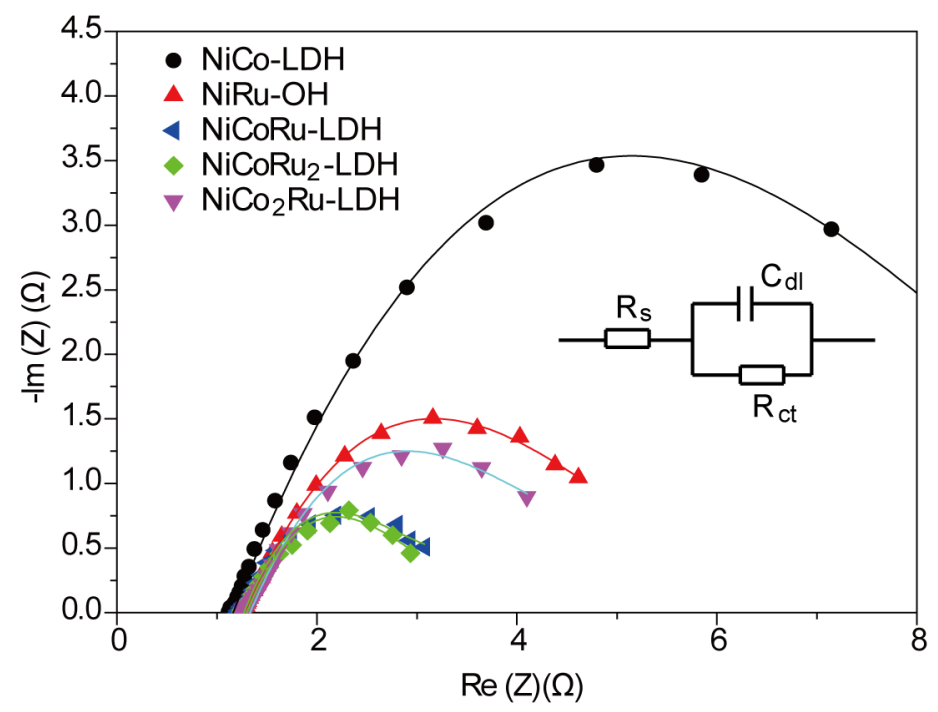

Figure S10. The EIS analysis for NiCo-LDH, NiRu-OH, NiCoRu-LDH, NiCo ${ }_{2} \mathrm{Ru}-\mathrm{LDH}$, and $\mathrm{NiCoRu}_{2}-\mathrm{LDH}$ toward OER. 
Table S1. Comparison of some representative OER catalysts reported under alkaline conditions.

\begin{tabular}{|c|c|c|c|c|}
\hline Catalysts & $\begin{array}{l}\text { Electrolyte } \\
\text { solution }\end{array}$ & Substrate & $\begin{array}{l}\text { Overpotentials (vs } \\
\text { RHE) at the } \\
\text { corresponding } j\end{array}$ & Reference \\
\hline $\begin{array}{c}\mathrm{FeOOH}_{2 \mathrm{~nm}} @ \mathrm{Ni}-\mathrm{Fe} \\
\mathrm{LDH}\end{array}$ & $\begin{array}{l}1.0 \mathrm{M} \\
\mathrm{KOH}\end{array}$ & GCE & $\begin{array}{l}\eta_{10}=174 \mathrm{mV} \\
\eta_{100} \approx 260 \mathrm{mV}\end{array}$ & $\begin{array}{c}\text { ACS Catal. 2018, } 8, \\
12,11342-11351\end{array}$ \\
\hline $\begin{array}{l}\text { Mo- and Fe-modified } \\
\mathrm{Ni}(\mathrm{OH})_{2} / \mathrm{NiOOH}\end{array}$ & $\begin{array}{l}1.0 \mathrm{M} \\
\mathrm{KOH}\end{array}$ & Ni foam & $\eta_{100}=280 \mathrm{mV}$ & $\begin{array}{c}\text { ACS Catal. 2018, } 8 \\
2359-2363 .\end{array}$ \\
\hline $\mathrm{W}_{0.5} \mathrm{Co}_{0.4} \mathrm{Fe}_{0.1} / \mathrm{NF}$ & $\begin{array}{l}1.0 \mathrm{M} \\
\mathrm{KOH}\end{array}$ & Ni foam & $\eta_{100}=310 \mathrm{mV}$ & $\begin{array}{c}\text { Angew. Chem. Int. Ed. } \\
\text { Engl. 2017, 56, } \\
\text { 4502-4506. }\end{array}$ \\
\hline $\mathrm{FeOOH} / \mathrm{CeO}_{2}$ & $\begin{array}{l}1.0 \mathrm{M} \\
\mathrm{NaOH}\end{array}$ & $\mathrm{Ni}$ foam & $\eta_{100}=320 \mathrm{mV}$ & $\begin{array}{c}\text { Adv. Mater. 2016, } 28, \\
\text { 4698-4703. }\end{array}$ \\
\hline NiCo-LDH & $\begin{array}{l}1.0 \mathrm{M} \\
\mathrm{KOH}\end{array}$ & $\begin{array}{l}\text { Carbon } \\
\text { paper }\end{array}$ & $\eta_{10}=367 \mathrm{mV}$ & $\begin{array}{c}\text { Nano Letters } 2015 \text {, } \\
15,1421-1427\end{array}$ \\
\hline $\mathrm{Ni}-\mathrm{Fe}-\mathrm{OH} @ \mathrm{Ni}_{3} \mathrm{~S}_{2} / \mathrm{NF}$ & $\begin{array}{l}1.0 \mathrm{M} \\
\mathrm{KOH}\end{array}$ & $\mathrm{Ni}$ foam & $\eta_{100}=300 \mathrm{mV}$ & $\begin{array}{l}\text { Adv. Mater. 2017, } 29 \text {, } \\
1700404 .\end{array}$ \\
\hline $\mathrm{Fe}: \mathrm{Ni}(\mathrm{OH})_{2}$ & $\begin{array}{l}1.0 \mathrm{M} \\
\mathrm{KOH}\end{array}$ & $\mathrm{Ni}$ foam & $\eta_{100}=300 \mathrm{mV}$ & $\begin{array}{c}\text { Science } 2014,345, \\
1593-1596 .\end{array}$ \\
\hline NiCoRu-LDH & $\begin{array}{l}1.0 \mathrm{M} \\
\mathrm{KOH}\end{array}$ & Ni foam & $\eta_{100}=270 \mathrm{mV}$ & This work \\
\hline
\end{tabular}




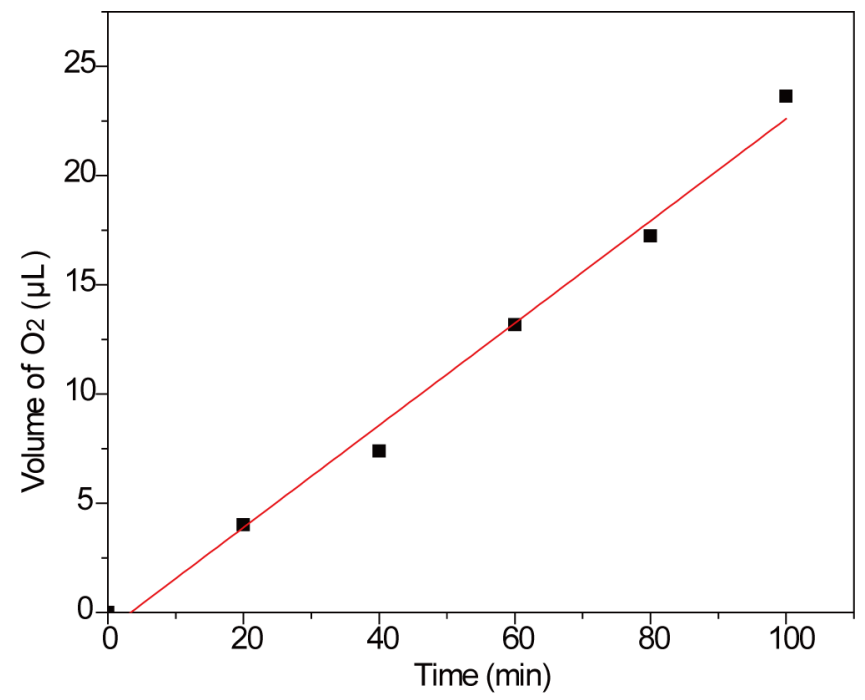

Figure $\mathrm{S} 11$. The volume of $\mathrm{O}_{2}$ generated by the NiCoRu-LDH/NF for OER. 


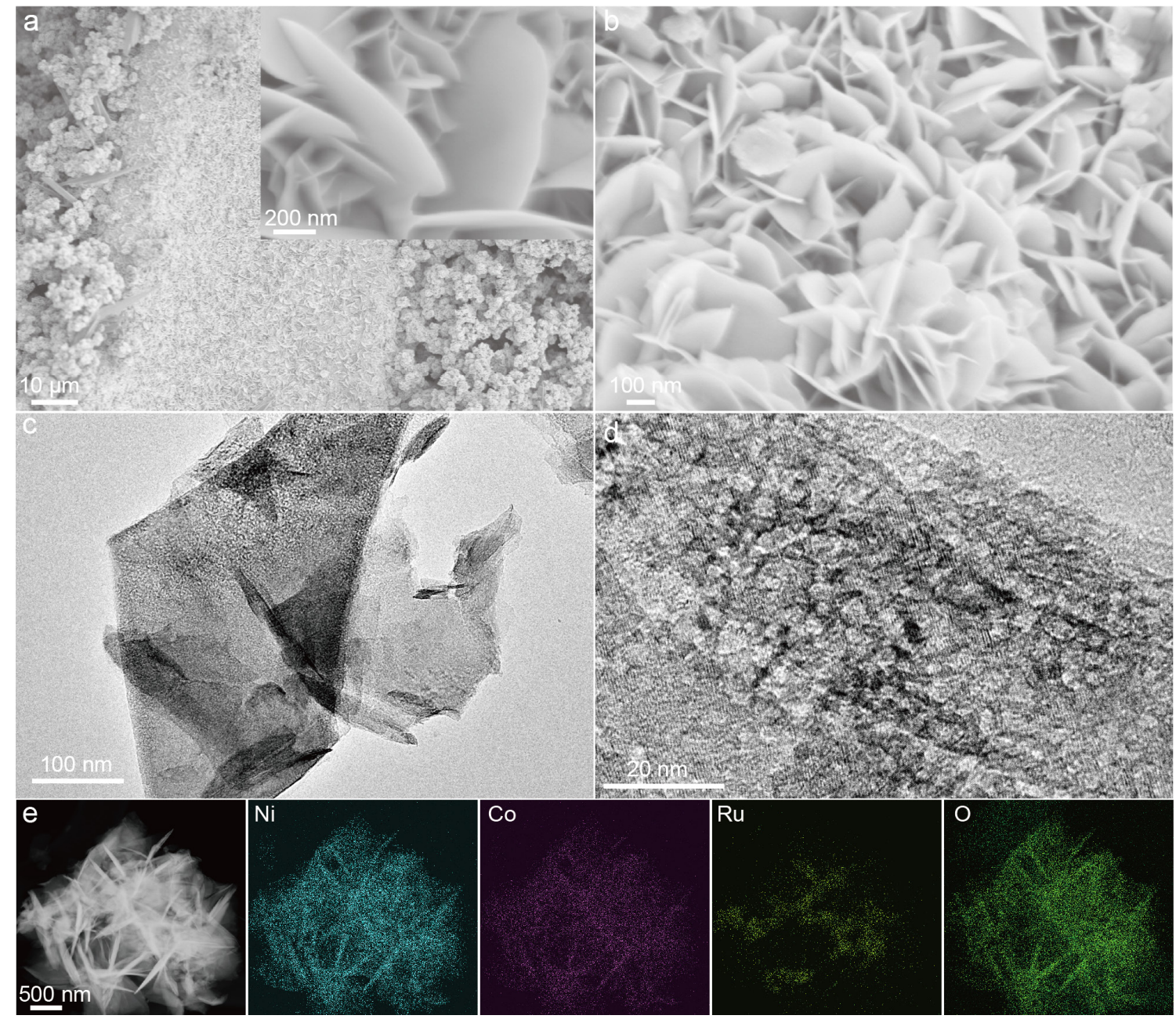

Figure S12. (a, b) SEM images for NiCoRu-LDH. (c) TEM image for NiCoRu-LDH. (d) HR-TEM image for

NiCoRu-LDH. (e) Elemental maps for NiCoRu-LDH after OER reaction. 


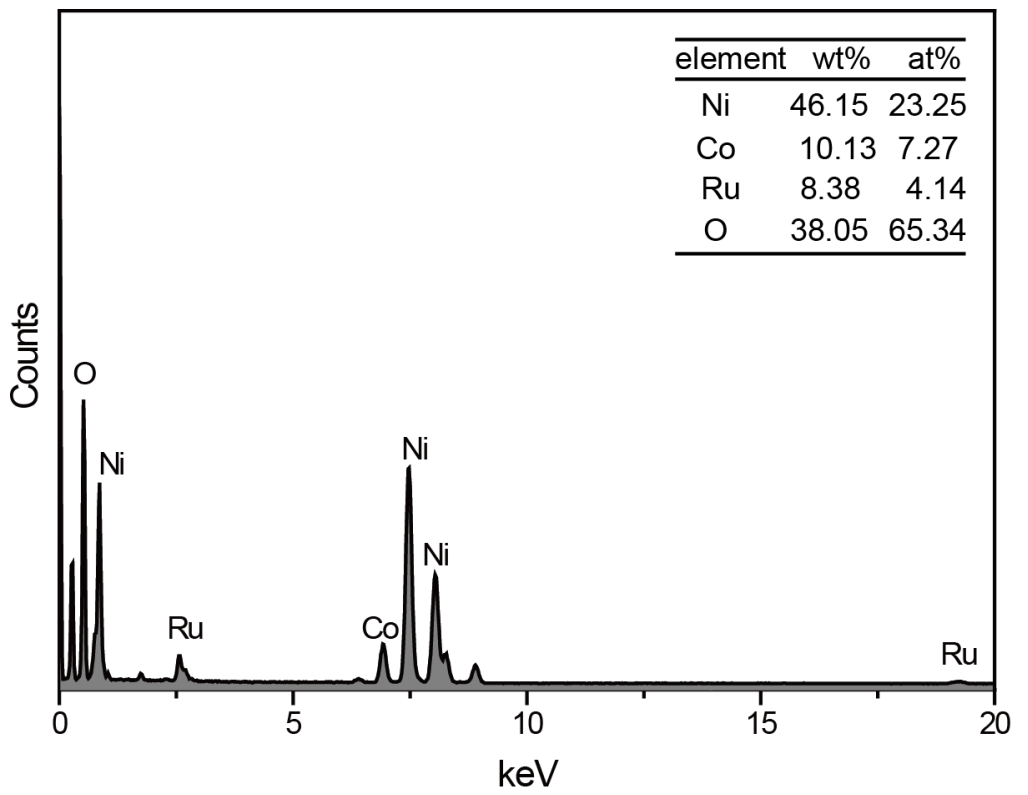

Figure S13. EDX spectrum for NiCoRu-LDH. 


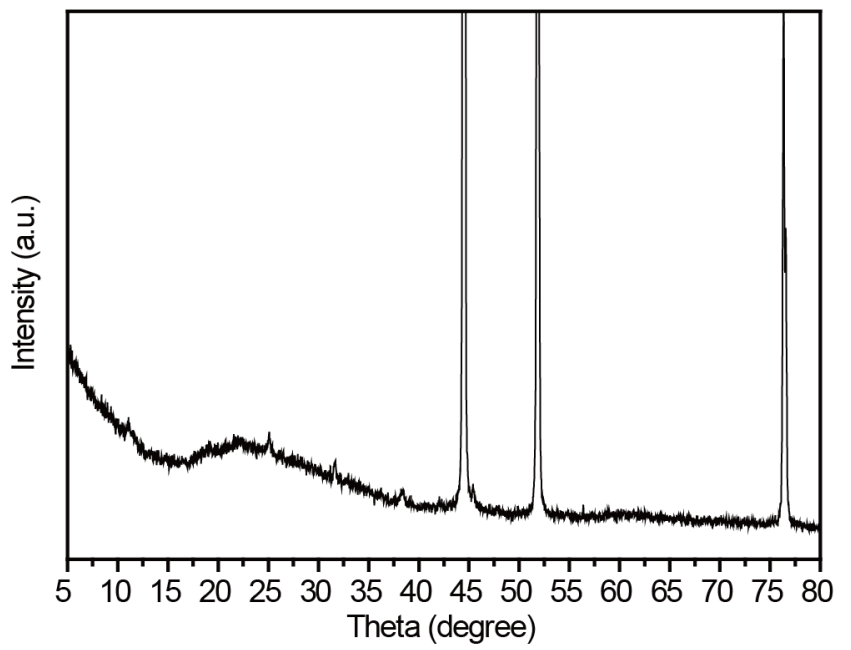

Figure S14. XRD pattern for NiCoRu-LDH after OER reaction. 